\title{
Content Analysis on the ERP Technology Implementation
}

\author{
Adriana Grigorescu ${ }^{1, *}$ Amalia-Elena Ion ${ }^{2}$ \\ 1,2 National University of Political Studies and Public Administration, Bucharest, Romania \\ "Corresponding author.Email: adriana.grigorescu@snspa.ro
}

\begin{abstract}
The competitiveness of the global market has been challenging for the SME sector for quite some time. Generally, good management will increase the chances of a small business to continue its activity on the market and even further develop it. Along with the Internet-of-Things, a wide array of management systems have been upgraded to offer business solutions to modern enterprises. The ERP system has had a significant history, but at the intersection with new technologies, it has adopted a new framework comprising of sustainability, open issues, architecture, knowledge management, innovation, etc. The current research is based on a content analysis of the most recent scientific research, as it illustrates the components of a successful ERP implementation at the convergence between SMEs and ERP technology systems.
\end{abstract}

Keywords: Enterprise Resource Planning, Internet of Things, Small and Medium-sized Enterprises, Information/Knowledge Management.

\section{INTRODUCTION}

During the last few decades, the world has passed through many crisis situations, determining the need for sudden change, while the general trends at global scale have evolved towards digitalization, glocalization, and user-focused strategies. Some of those opportunities are easy to implement for many of the active enterprises, while others seem a bit strenuous to adhere to. Considering that $90 \%$ of all businesses worldwide are SMEs, and they employ $50 \%$ of the overall workforce [1], small and medium enterprises are truly contributing to the development of the economy and providing a significant input in job creation. Moreover, by 2030, over 600 million jobs will be added to contain the ever-growing global workforce, with SMEs covering 7 out of 10 jobs. Consequently, the SME sector must take measures to ensure the equilibrium between growing trends and value-added in the economy.

Such change can only be tackled through previous strategic management, including perspectives regarding the financial viability of the former. From this point of view, SMEs are less likely to obtain funding compared to large enterprises, as they heavily rely on their own capital. According to the World Bank (2021) [1], 40\% of the SMEs in emerging countries need $\$ 5.2$ trillion every year, equivalent to 1.4 times the current level of global SME lending. This financial gap is determined by several factors, including the limited knowledge at SME sector level, the lack of proper strategic management planning, or the inability to cope with change. The last three mentioned aspects are very much related to what the ERP system implementation would achieve within the small and medium enterprises, although it comes, as below stated, with a significant cost, which brings the circle to a close. The reason behind limited financing in the SME sector comes from limited knowledge of both internal and external factors influencing the long-term development of the enterprise, while the knowledge can only be achieved through enough funds invested in research \& development and better resource planning.

Nevertheless, the paper addresses the importance of resource planning systems within the SME sector for consistent development and a sufficient valueadded translation in the global economy. The ERP system has the capacity to allow enterprises to plan, budget, forecast and communicate the status of the organization to all stakeholders. Although it implies considerable finances for implementation, the system increases the accuracy rate of the business, allocates 
resources efficiently, and manages to decrease the overall operational costs of the enterprise. In order to achieve those results, the ERP system must first follow a set of rules for successful implementation, as extensively discussed in the literature. The current study is built around a content analysis of various research from 2019-2021 regarding the implementation stage of the ERP system and provides a framework for the successful realization of work synchronization and real-time reporting through a single source system. The paper also underlines the importance of a resource planning system for SMEs, based on new technologies that would align to Six Sigma perspectives.

\section{LITERATURE REVIEW}

As the market competition increases, the enterprises try to work around different solutions in order to keep up with the changing trend. Efficiency and efficacy represent some of the most used words in relation to the activities and operations of any organization. From the development of the Six Sigma techniques for process improvement, to the agile management framework, the overall methodology for business management processes has evolved with the scope of an efficient organization of activities and operations for the ultimate purpose of customer satisfaction, reduction of variation, and data-driven quality strategies.

The ERP is the acronym for enterprise resource planning, and it represents a system that allows a company to plan and manage daily resources based on their interconnectivity across departments, including supply chain, manufacturing, finance, services, processes, etc. The main currency of the ERP system is data. Based on the latter, the computer software that programs all the daily operations and resources of the enterprise has the ability to automate all the business functions of the departments production, sales, accounting, etc. [2]. The automation is sustained by different hardware solutions, such as scanners, labelling systems, printers, etc. The software uniquely identifies each resource within the company, and automatically allocates it to the department that needs it. The resources might be physical materials and/or intangibles, such as reports and other interpreted information. This solution brings high interdepartmental efficiency, and the capacity to foresee change or shifts, while quickly adapting to them [3]. It also showcases liabilities within the enterprise and gives way to the adoption of new techniques and/or processes that have a positive impact on the organization. Among the most used ERP software solutions are the SAP, the Oracle applications, and the Microsoft Dynamics AX, all based on the same principles: enterprise-wide integration, real-time operations, common database, consistency.

Moreover, an ERP system is critical for an enterprise due to its capacity to serve a shared database for all important information across the company, to give access to employees to the latter and to answer questions related to the current performance of the enterprise and the future planning of its operations [4]. This means that all stakeholders within the company will have the same information available, thus the consistency principle will be achieved, while driving for better decision-making processes and leading towards cost savings and higher efficiency. Most commonly the ERP is catered based on the needs of the given enterprise, as various modules can be plugged into the ERP system to bring a customized modular solution. Notoriously, there are 13 ERP modules, comprising of finance and accounting, procurement, manufacturing, inventory management, order management, warehouse management, supply chain management, CRM, project management, workforce management, HR, ecommerce, and marketing automation [5]. Each module has its own purpose and cost, and it can be implemented only if the company requires. The choice in the selection of the ERP modules is based on several factors, such as the business model, the industry in which the enterprise is active, the status of the global economy, the opportunities and threats within the sector, the competition, the consumer behaviour, as well as internal factors related to the financial capacity of the enterprise, the available human capital, the knowledge within the company, etc. Generally, the most used modules in the ERP system are finance and accounting, CRM, HRM, supply chain management, as well as e-commerce and marketing automation.

During the last decades, the ERP solutions have experienced growth and maturity, reaching in 2021 front and back-end processes through the usage of new technology. For instance, the cloud ERP market is expected to increase by at least 13 percentage points annually, and to reach in 2025 the significant market value of $\$ 40$ billion [6]. Moreover, the artificial intelligence and machine learning will optimize the business processes through the development of new personalized user interactions 
and insights. Also, the ERP is currently integrating technologies such as IoT devices and social media, and it even supports the new human capital trend remote work. The digital transformation wave has been significant on the altering of business functions. In a 2020 Accenture report [7], three quarters of the UK based enterprises using ERP are having a cloudbased solution integrating their core business functions and strategies. Although this is the case, for almost half of the companies included in the study the ERP integration was not completed in 2020, showcasing the fact that the learning curve is steeper than expected, and that the need for a clear, straightforward ERP implementation framework is needed.

\section{RESEARCH METHODOLOGY}

Among the qualitative analysis methods, content analysis is one of the most popular, bridging the data within various research into a consistent overview, based on the context units specific to the subject of analysis. In this case, the content analysis was performed on 49 scholar research, referring to the perspectives of ERP system implementation, and transferred the knowledge into a unitary module for general use.

The first step of the content analysis was represented by the manual and random selection of the scientific articles included for research. Each article was identified based on the DOI number, after a Google Scholar search relevance attribution consistent with the phrase ERP system implementation, and with the publishing date (20192021). Moreover, the articles have been analysed in rapport to the phases of the ERP implementation process, after the selection of the recording units within the context of the scientific papers (Table 1).

Table 1. Selected research \& content analysis

\begin{tabular}{|c|c|c|c|}
\hline $\begin{array}{c}\text { Research } \\
\text { paper }\end{array}$ & Code & $\begin{array}{l}\text { Recording unit } \\
\text { codes }\end{array}$ & Recording units \\
\hline \multirow[t]{2}{*}{$\begin{array}{l}\text { Chofreh et al. } \\
{[8]}\end{array}$} & A & A1 - A9 & $\begin{array}{l}\text { Strategic analysis; strategic alignment; system strategy; resource analysis; } \\
\text { change management analysis; agility and responsiveness; tangible resources; } \\
\text { intangible resources include human, innovation and reputational resources; } \\
\text { business case analysis }\end{array}$ \\
\hline & B & $\mathrm{B} 1-\mathrm{B} 7$ & $\begin{array}{l}\text { Knowledge and material inflows and outflows; mediating and moderating } \\
\text { mechanisms to predict adoption; mediation exists from facilitating condition } \\
\text { to the actual use of ERP; users' passion and inclination toward behavioural } \\
\text { intention to use ERP; neither the impact of education nor the effect of firms' } \\
\text { size significantly influences; module-based application programs of ERP } \\
\text { software are highly regarded; positive direct influence of organisation size } \\
\text { on actual use of ERP }\end{array}$ \\
\hline Zafary [9] & $\mathrm{C}$ & $\mathrm{C} 1-\mathrm{C} 17$ & $\begin{array}{l}\text { Non-pyramid structures, appropriate communication and management styles; } \\
\text { training, learning, nurturing talents and ethics/improvement of the working } \\
\text { behaviour of personnel; knowledge sharing as a problem-solving strategy; } \\
\text { better understand internal and external components; technology utilisation } \\
\text { has significant role; management of information; skilled personnel; reverse } \\
\text { engineering and value chain; train manpower; periodic training and } \\
\text { monitoring; organisational coherence; reinforcement of virtual } \\
\text { communication; suggestions and critics of personnel; enhance the culture of } \\
\text { technology use; information exchange; specialised training; knowledge- } \\
\text { based strategies }\end{array}$ \\
\hline $\begin{array}{l}\text { Tavana \& } \\
\text { Oveisi [10] }\end{array}$ & $\mathrm{D}$ & D1 - D12 & $\begin{array}{l}\text { IoT one of the key technologies working with ERP; big data analysed online } \\
\text { to acquire useful knowledge; dynamic systems; processing large number of } \\
\text { events and alerts; integration between the devices and business; intelligent } \\
\text { mechanism for prediction; deep learning/machine learning; } \\
\text { chatbots/responses in real-time; cloud computing ERP; sensor networks; } \\
\text { real-time interactions; flexible and strong security protocols }\end{array}$ \\
\hline $\begin{array}{l}\text { Ferrari, } \\
\text { Settembre- } \\
\text { Blundo, }\end{array}$ & E & E1 - E6 & $\begin{array}{l}\text { Life cycle assessment; direct exchange of data; real-time information; } \\
\text { business intelligence; IoT technologies enabling for environmental } \\
\text { sustainability; industry } 4.0\end{array}$ \\
\hline
\end{tabular}


Garcia-

Muiña [11]

\begin{tabular}{|c|c|c|c|}
\hline $\begin{array}{l}\text { Santos\& } \\
\text { Martinho } \\
{[12]}\end{array}$ & $\mathrm{F}$ & $\mathrm{F} 1-\mathrm{F} 6$ & $\begin{array}{l}\text { Scheduled routines; retry mechanism for temporary issues; automated } \\
\text { synchronisation processes; open-source technologies; data synchronisation; } \\
\text { inter-application middleware }\end{array}$ \\
\hline $\begin{array}{l}\text { Krithika, } \\
\text { Deepa \& } \\
\text { Bhavanasi } \\
{[13]}\end{array}$ & G & $\mathrm{G} 1-\mathrm{G} 10$ & $\begin{array}{l}\text { High amount of coding; efficient use of available resources; building } \\
\text { communities; skills or knowledge for the usage of services and platforms; } \\
\text { data to be synchronised; test software application; adequate training; risk of } \\
\text { errors; redundancy of information; ERP gadgets }\end{array}$ \\
\hline
\end{tabular}

Goundar et $\quad \mathrm{H} \quad \mathrm{H} 1-\mathrm{H} 6$

al. [14][15]

Adaptive system modules; quickly build and deliver modules upon request; flexibility and automation; improved quality by finding and fixing faults; user acceptance and training; change management

$\begin{array}{lll}\text { Oh et al. [16] } & \text { I } & \text { I1 - I3 } \\ \text { Oh et al. [16] } & \text { J } & \text { J1 - J6 }\end{array}$

Activity mapping; reflecting the opinions of working-level staff; the consensus of experts

Synergies between the resources of the organisation; user training; senior management commitment; selecting the right software package; change management; application interconnectivity

Malik \&

$\mathrm{K} \quad \mathrm{K} 1-\mathrm{K} 5$

Khan [17]

Goundar et

L $\quad$ L1 - L5

al. [14][15]

Tarigan et al. $\quad \mathrm{M} \quad \mathrm{M} 1-\mathrm{M} 4$

Husain [19] $\quad \mathrm{N} \quad \mathrm{N} 1-\mathrm{N} 3$

Roy \& $\quad$ O $\quad$ O1 - O9

Sangle [20]

Amado \&

Thang [22]

$\mathrm{P} \quad \mathrm{P} 1-\mathrm{P} 2$

$\begin{array}{lll}\text { Kakkar [23] } & \text { Q } & \text { Q1 - Q2 } \\ & \text { R } & \text { R1 } 1-\text { R4 }\end{array}$

Success close linked to humans and less about the technology; right timing for implementation; maximum possible resources; computer-based training; build trust

Time flexibility; awareness technologies; good training evaluation; unified support system; change management

Effective design of business processes; suitability; data management integration; key user capability

Training; vendor support; knowledge management

Technology consulting partner; involving stakeholders across the company; readiness of hardware infrastructure; support strategy; super users; transition process; web-based training; job impact analysis; customised change strategy

Maintenance and support activities; package parametrization

Adaptive solutions; frequent interaction

Provider with deep knowledge; clear experience in industry; cloud integration; AI, machine learning and IoT

Yoo \& Kim $\quad \mathrm{S} \quad \mathrm{S} 1-\mathrm{S} 2$

Utomo et al., $\quad \mathrm{T} \quad \mathrm{T} 1-\mathrm{T} 3$

2021[25]

Dasgupta \& $\quad$ U $\quad$ U1 - U4

Nayak [26]

Gavidia,

Junlas, \&

Chou [27]

Bender \&

Gronau [28]

Customisation; correlation between ERP construction, type, and unit company

Analysis of financial data; effective and integrated results; transaction data accuracy

Team planning; leadership skills; knowledge about ERP system implementation; autonomy and work flexibility

Jesus \& Lima

[29]

W $\quad \mathrm{W} 1-\mathrm{W} 3$

User satisfaction; system use; information quality; operational control

$\mathrm{X}$

$\mathrm{X} 1-\mathrm{X} 3$

$\mathrm{V} \quad \mathrm{V} 1-\mathrm{V} 4$

Architecture of enterprise systems; user interface; adaptation layer

External support; training; user acceptance 


$\begin{array}{lcc}\begin{array}{l}\text { Ploder et al. } \\ \text { [30] }\end{array} & \text { Y } & \text { Y1 - Y2 } \\ \begin{array}{l}\text { Skorkovský } \\ \text { \& Duranti } \\ \text { [31] }\end{array} & \text { Z } & \text { Z1 - Z2 } \\ \begin{array}{l}\text { Nobari \& } \\ \text { Hossein [32] }\end{array} & \text { AA } & \text { AA1 - AA4 } \\ \begin{array}{l}\text { Riskiana et } \\ \text { al. [33] }\end{array} & \text { BB } & \text { BB1 - BB2 } \\ \begin{array}{l}\text { Domagala et } \\ \text { al. [34] }\end{array} & \text { CC } & \text { CC1 - CC2 } \\ \begin{array}{l}\text { Hietala \& } \\ \text { Päivärinta } \\ \text { [35] }\end{array} & \text { DD } & \text { DD1 - DD2 } \\ \begin{array}{l}\text { Elhasnaoui } \\ \text { [36] }\end{array} & \text { EE } & \text { EE1 - EE5 } \\ \begin{array}{l}\text { Chatti \& } \\ \text { Zaghdan [37] }\end{array} & \text { FF } & \text { FF1 - FF3 } \\ \begin{array}{l}\text { Al Bar, et al. } \\ \text { [38] }\end{array} & \text { GG } & \text { GG1 - GG2 } \\ \begin{array}{l}\text { Budiman et } \\ \text { al. [39] }\end{array} & \text { HH } & \text { HH1 - HH3 } \\ \begin{array}{l}\text { Huang et al. } \\ \text { [40] }\end{array} & \text { II } & \text { II1 - II8 } \\ \end{array}$

Nach \&

Lejeune [41]

Dasgupta \& Bhadauria

[42]

$\begin{array}{lll}\text { Gërvalla [43] } & \text { LL } & \text { LL1 - LL3 } \\ \begin{array}{l}\text { Etehadnezha } \\ \text { d et al. [44] }\end{array} & \text { MM } & \text { MM1 - MM2 }\end{array}$

Ylätupa [45] $\quad$ NN $\quad$ NN1 - NN5

Istanbouli $\quad \mathrm{OO} \quad \mathrm{OO} 1-\mathrm{OO} 3$

[46]

Bhatt et al. PP

[47]

Nguyen et al. [48]
Cloud solution implementation does not reduce the costs; immediate scalability

Tacit knowledge; national parameters affecting the risk factors of ERP implementation

User involvement; training \& education; customisation; change management

Saturation of ERP market; mass customisation manufacturing

Complicated by local workarounds; long ERP lifecycle complicates the benefits

Establishing an IT governance framework; set measurable goals, policies, and practices

Involvement of end-users; training sessions; communication to promote acceptance; flexibility; change management

Customisation; marshalling all stakeholders; project control

Mapping of information systems; repeated resource usage

Multi-tenant feature of the cloud; standard encryption/decryption techniques; contingency theory

Investment in innovation technology a CSF (critical success factor); teamwork and team composition; change management culture; ERP failure if change in business vision; corporate culture; change management competencies; nature, culture and tradition of organisation; vendor relationship management

Learning system; online cooperation platforms; training and decisionmaking support

IT based cloud solution; similarity and connection between data and information within an organisation; collaboration of the supply chain management system; top management involvement and awareness; hybrid methodology for ERP implementation; employee productive, innovation \& service quality

Maturity model of implementation; future digitalisation; integration of technologies in support of industry 4.0

Components impacting on ERP utilisation in education: organisational: organisational strategy and policy organisational breadth and complexity, business processes, organisational culture, skill and capability, shared values and beliefs; trust \& honesty, independence, intrinsic motivation

Feedback of communication issues; remote approach worked well; knowledgeable corporate team; good communication tools; pressure testing before implementation

Modularise initial business processes; increase awareness of implementation team; create blueprints of smaller modules of supply chain processes

Factors affecting ERP procurement decision: cost of deployment, user friendliness and security, need fulfilment, vendor credibility

Because of the inclusion of the accounting department in the ERP system are increased business flexibility, increased integration of accounting 


\begin{tabular}{|c|c|c|c|}
\hline $\begin{array}{l}\text { Sebayang et } \\
\text { al. [49] }\end{array}$ & $\mathrm{RR}$ & $\mathrm{RR} 1-\mathrm{RR} 4$ & $\begin{array}{l}\text { Internal integration; cross-functionality between departments; automate the } \\
\text { determination of company's lead time and stock; on-time delivery and } \\
\text { accuracy }\end{array}$ \\
\hline $\begin{array}{l}\text { Maslii et al. } \\
{[50]}\end{array}$ & SS & SS1 - SS5 & $\begin{array}{l}\text { Business process map; automation; efficient, adaptable and secure IT } \\
\text { infrastructure; information flow; single mechanism for accessing information } \\
\text { resources of AI }\end{array}$ \\
\hline $\begin{array}{l}\text { Wijaya \& } \\
\text { Utomo [51] }\end{array}$ & TT & TT1 - TT5 & $\begin{array}{l}\text { Focus on technical aspects; minimising the number of modifications; } \\
\text { documentation is also a success factor; knowledge management a key } \\
\text { success factor; change management }\end{array}$ \\
\hline Goni [52] & UU & UU1 - UU2 & $\begin{array}{l}\text { Implementation roadmap; integration, knowledge, scope, cost, risk, human } \\
\text { resources, procurement }\end{array}$ \\
\hline $\begin{array}{l}\text { Utama \& } \\
\text { Nur'ainy [53] }\end{array}$ & VV & VV1 - VV4 & Top management sponsorship; scope; change management; education \\
\hline $\begin{array}{l}\text { Rana et al., } \\
2021[54]\end{array}$ & WW & WW1 - WW4 & $\begin{array}{l}\text { Strong training programmes; user involvement; change management; } \\
\text { guidance and commitment of top management }\end{array}$ \\
\hline
\end{tabular}

applications, enhanced quality of reports, improved decision-making process, reduction of time for transaction processing; convenience of access

Source: Author's synthesis.

The second part of the research comprised of the attribution of recording units from each research paper to one of the following categories identified: analysis and planning, resources and budget, change management, development and migration, testing and training (Table 2).

Table 2. Allocation of categories for the study

\begin{tabular}{ll}
\hline Category name & Meaning \\
\hline Analysis \& planning & $\begin{array}{l}\text { The first category refers to all the information gathered from within and outside the } \\
\text { enterprise and analysed in order to disclose the business model of the latter, } \\
\text { alongside the planification of the digital transformation of the business, including } \\
\text { benefits, risks, costs, objectives, as well as resources required and timeline. }\end{array}$ \\
The second category represents the identification of the resources allocated for the \\
ERP implementation, especially the team that will conduct the change process and \\
the digital transformation, and the realistic funds needed for the implementation \\
process (considering possible roadblocks, unexpected costs, and delays). \\
The third category refers to the tasks that are mandatory to ensure the transition \\
from fragmented processes to the ERP system, including the forecasting, the \\
roadmap for implementation, communication guidelines, progress tracking, and risk \\
management. \\
The fourth category comprises of the matching of functional requirements, process \\
flows, as well as wireframes, based on a customized solution for the enterprise. The \\
development team writes new software and integrates the ERP system within the \\
enterprise alongside the migration of data, setting up the database types and \\
formats, and protocols for handling missing, incomplete or erroneous data.
\end{tabular}

Source: Author's synthesis.

The third part of the study was the frequency analysis, by manually correlating the recording units to the categories indicated above. Each recording unit allocation was counted for a certain category, underlining the importance attributed by theoretical 
and applicative studies on the ERP dimension. The

information is described in Table 3 .

Table 3. Frequency analysis

\begin{tabular}{|c|c|c|c|}
\hline Category & Recording unit & Frequency & $\%$ \\
\hline Analysis \& planning & $\begin{array}{l}\text { A1, A2, A3, A4, A5, A9, B6, C4, C6, C8, C17, } \\
\text { E1, F1, I1, J4, K2, L1, M1, N3, O4, O8, R2, T1, } \\
\text { Z2, BB1, FF3, GG1, II5, II7, KK5, LL1, MM1, } \\
\text { QQ1, QQ2, SS1, TT3, UU1, VV2 }\end{array}$ & 38 & $17.5 \%$ \\
\hline Resources \& budgeting & $\begin{array}{l}\text { A7, A8, C5, E2, E3, E4, F4, G2, G10, J1, J3, K3, } \\
\text { U3, Z1, CC1, CC2, FF2, GG2, HH3, II1, II4, } \\
\text { KK4, NN3, PP1, RR2, TT4, UU2, VV1, WW4 }\end{array}$ & 29 & $13.5 \%$ \\
\hline Change management & $\begin{array}{l}\text { A6, C11, G8, G9, H1, H5, I2, I3, J5, K5, L4, L5, } \\
\text { O2, O6, O9, U2, U4, X3, AA4, DD2, EE3, EE4, } \\
\text { EE5, II3, II6, KK2, MM2, NN1, NN2, NN4, OO2, } \\
\text { SS4, TT2, TT5, VV3, WW3 }\end{array}$ & 36 & $16.5 \%$ \\
\hline Development \& migration & $\begin{array}{l}\text { B2, B3, B7, B8, C1, D1, D3, D4, D5, D6, D7, D8, } \\
\text { D9, D10, D11, D12, E5, E6, F2, F3, F5, F6, G1, } \\
\text { H2, J6, L2, M2, M3, N2, O3, P2, Q1, R3, R4, S1, } \\
\text { S2, T2, T3, V2, V3, V4, W1, W2, W3, Y1, Y2, } \\
\text { AA3, BB2, DD1, FF1, HH1, HH2, JJ2, KK1, } \\
\text { KK3, LL2, LL3, OO1, OO3, RR1, RR3, RR4, } \\
\text { SS2, SS3, SS5, TT1 }\end{array}$ & 66 & $30 \%$ \\
\hline Testing \& training & $\begin{array}{l}\text { B1, B4, C2, C3, C7, C9, C10, C12, C13, C14, } \\
\text { C15, C16, D2, G3, G4, G5, G6, G7, H3, H4, J2, } \\
\text { K1, K4, L3, M4, N1, O1, O5, O7, P1, Q2, R1, U1, } \\
\text { V1, X1, X2, AA1, AA2, EE1, EE2, II2, II8, JJ1, } \\
\text { JJ3, KK6, NN5, VV4, WW1, WW2 }\end{array}$ & 49 & $22.5 \%$ \\
\hline
\end{tabular}

Source: Author's synthesis.

The results of the frequency analysis showcase the importance given to ERP implementation phases as following: highest level of importance is given to the development of the software integration and migration of data to the new ERP system, while the lowest level of importance is given to resources and budgeting. Second most important level is attributed to the testing of the software capacity and functionality, as well as the personnel training for the usage of the ERP system, followed by third most important element - the analysis and planning phase of the ERP implementation process. Second to last based on attributed importance was the change management phase of the ERP implementation.

\section{DISCUSSION}

Organizations worldwide have acknowledged the necessity to adopt the enterprise resource planning systems with the scope of leveraging their business performance and the level of value-added in the economy. Since the market comprising of large enterprises is already saturated in terms of adoption of ERP systems, the focus is currently on the growing sector of SMEs, which, as already mentioned, represents the backbone of the global economy by covering the highest proportion of job creation sources and of value-added.

The alteration of the ERP solutions for SMEs has been representative cost-wise, as cheaper implementation services have been catered to this market. Nevertheless, the financial aspects surrounding the SMEs are not the only ones hindering the smooth adherence to ERP systems. One of the most evident cases is that of ERP service providers not fully understanding the basic differences between the large enterprises and the SMEs, starting with the dimension of knowledge and training, a general and constant problem for SMEs in rapport to any other perspective (i.e., funding, $R \& D$, business development, technology adoption/digitalization, etc.). Such aspects are fundamental in the understanding of how the ERP implementation will undergo in the case of SMEs.

By observing the results obtained, it can be mentioned that the focus is not evenly divided across the 5 categories or phases of the ERP implementation, as described in this paper. There is an unbalance of forces and factors influencing the 
adherence to such a resource planning system. Although to some extent expected, the results portray a phenomenon that is very much linked to a fundamental gap in the SME management - change management. Nowadays. change is one of the most important and consistent aspects within the global economy, and, during the adherence phases to the ERP system, it represents one of the most significant elements, as it covers the shifts in the daily routines, including the risk assessment on behalf of the human capital. The change management is based on a Six Sigma methodology, which makes the change controlled and effective. By using SIPOC diagrams, the implementation team can manage to produce the right outputs for the correct target group in a comprehensive manner, including aspects such as suppliers (Who supplies the process inputs?), inputs (What inputs are required?), processes (What are the major steps in the process?), outputs (What are the process outputs?), and customers (Who receives the outputs?). The change strategy can be based on Kotter's 8-step Change Model, the Change Curve, or the ADKAR Change Management Model, and it comprises of the need to change, the key objectives of the transition, the benefits for the enterprise, the impact it will have on the employees, the shift in the daily routines, and the necessary elements to ensure a successful implementation. The latter is a rare occurrence, since $2 / 3$ of the ERP implementation either fails, or they determine substantial extra costs.

Which leads to the next significant aspect disclosed in this study, namely the first less important and discussed phase of the ERP implementation budgeting. It is easy to foresee significant cost sources when budgeting for the ERP system, especially in the situation of SMEs, where the knowledge transfers occur at a lower rate compared to large enterprises. Generally, in business, the plan does not necessarily align with the reality. When budgeting, not only it is important to acquire enough knowledge regarding the internal operations and processes, but to also understand the movements occurring outside the enterprise. It is fundamental to be able to realistically anticipate trends, events, roadblocks, etc., and to plan accordingly, by having a contingency budget available in case of unexpected costs and/or delays. During the project implementation, this aspect can be further adjusted so that it continues to stay relevant.

The third to last by importance level in the research has been the analysis and planning phase, which comprises of the collection of information regarding the internal and external influences, and it provides a foundation for the ERP solution. At this stage, the project objectives should be outlined, alongside the planned methods for accomplishment. For an SME, the ERP implementation represents one of the biggest digital transformations that can occur with the sector, fundamentally changing the entire business model, the operations and activities performed, the roles with the enterprise, as well as the outputs of the latter. The planning phase should comprise of the resources required for the project, the timeline of implementation, and the change management perspectives (i.e., selection of change management strategy).

As observed from this research, the focus during the ERP implementation system in SMEs is driven towards the development of modules/software and migration of data, as well as the testing of the solution and the training of the personnel. It is quite significant that the SMEs do indeed attribute consistency and importance to those phases, although it is fitted to understand that without a proper followthrough of the other ERP phases, the system cannot be successfully implemented.

\section{CONCLUSIONS}

This study has managed to underline the uneven attention given to the different phases of the ERP system implementation in the case of SMEs, the consequences of it, as well as the measures to ensure a balanced account on all the described elements. There were 5 phases included in the ERP implementation system, namely analysis \& planning, resources \& budgeting, change management, development \& migration, and testing \& training. For each category, a series of recording units have been attributed, based on the context described in the selected scientific research papers. The frequency analysis has disclosed the distribution by allocated space and importance within research to each category or phase of the ERP system implementation, particularly related to the case of SMEs.

The results showcased that there is an unbalanced perspective on the importance of various phases of implementation, with software development and data migration taking centre stage, followed closely behind by testing of software and module solution and the personnel training. Although significantly positive, the results have portraited the diminished focus on budgeting and change management, two elements that, especially for the SMEs, can pose 
considerable problems, to the extent of failure to implement the project. The SMEs are vulnerable from various perspectives, including the resources they have at disposal, the ownership and management style, the culture and structure of the enterprise, the stage of growth and the market capitalization, the knowledge acquisition and transfer, as well as the technical expertise. For instance, the low level of resources available has an impact on the funding of the project, meaning that it is difficult to find financial and human resources, and this is directly influencing the training stage.

Moreover, the decision-making process within the enterprise significantly influences the ERP implementation, and the owner of the business is the key player in this regard, having the power to direct the result towards a positive or negative outcome. Also, the complexity of the internal structure of the enterprise is another aspect weighing on the project implementation, and here it might be assessed that the average organizational structure of SMEs represents an advantage due to their simplicity that facilitates communication and decision-making processes. In the end, the fundamental element for a successful ERP implementation in SMEs consists of the available knowledge regarding the project, the enterprise, the external environment, the phases of the implementation, and the resources.

Finally, the SMEs should improve their strategic planning and analysis, based on the available resources, and their motivation to adhere to digital transformation by eliminating complicated solutions, and recognizing the importance of constant outcome evaluation along the ERP system implementation phases. Although vulnerable, SMEs have certain advantages that could represent the key to successful ERP adherence, including their simplicity in structure, communication, and decision-making processes.

\section{AUTHORS' CONTRIBUTIONS}

The scientific relevance and contribution of the current research relies in the attributed categories for the study, which focus on the concentrated steps of the ERP implementation process, and in the correlations established with state-of-the-art data.

Moreover, the absorption of knowledge has been directed towards one of the most relevant economic drivers - SMEs. Based on the points accounted in this study, the research also contributed to the practicality of economic life, by establishing a clear view of the potential, benefits, risks, as well as steps in the ERP implementation for SMEs.

\section{REFERENCES}

[1] World Bank. Small and Medium Enterprises (SMEs) Finance. 2021. [Online]. Available from: World Bank SME Finance: Development news, research, data $\mid$ World Bank.

[2] Rajan, C. A., \& Baral, R. Adoption of ERP system: An empirical study of factors influencing the usage of ERP and its impact on end user. IIMB Management Review, vol. 27(2), pp. $105-117.2015$. DOI:10.1016/j.iimb.2015.04.008.

[3] Shang, S, \& Seddon, P.B. A Comprehensive Framework for Classifying the Benefits of ERP Systems. AMCIS 2000 Proceedings, pp. 39. 2000

[4] Zach, O., Munkvold, B. E., \& Olsen, D. H. ERP system implementation in SMEs: exploring the influences of the SME context. Enterprise Information Systems, vol. 8(2), pp. 309-335. 2012. DOI:10.1080/17517575.2012.702358

[5] Leon, A. ERP Demystified. Second Edition. New Delhi: McGraw-Hill. 2008.

[6] Statista. Forecast: Global cloud ERP revenue 2018 and 2022. 2020. [Online]. Available from: • Global cloud ERP revenue 2025 | Statista.

[7] Accenture. Turning intelligence into value. 2020. [Online]. Available from: Accenture-ERPReport-2020.pdf.

[8] Chofreh, A. G., Goni, F. A., Klemeš, J. J., Malik, M. N., \& Khan, H. H. Development of guidelines for the implementation of sustainable enterprise resource planning systems. Journal of Cleaner Production, pp. 118655. 2019. DOI: 10.1016/j.jclepro.2019.118655

[9] Zafary, F. Implementation of business intelligence considering the role of information systems integration and enterprise resource planning. Journal of Intelligence Studies in Business, vol. 10(1), pp. 59-74. 2020 DOI: 10.37380/jisib.v1i1.563

[10] Tavana, M., Hajipour, V., \& Oveisi, S. IoTbased Enterprise Resource Planning: Challenges, Open Issues, Applications, Architecture, and Future Research Directions. Internet of Things, 
$\begin{array}{llll}\text { pp. } & 100262 . & 2020 . & \text { DOI: }\end{array}$ 10.1016/j.iot.2020.100262

[11] Ferrari, A. M., Volpi, L., Settembre-Blundo, D., \& García-Muiña, F. E. Dynamic Life Cycle Assessment (LCA) integrating Life Cycle Inventory (LCI) and Enterprise Resource Planning (ERP) in an Industry 4.0 environment. Journal of Cleaner Production, pp. 125314. 2020. DOI: 10.1016/j.jclepro.2020.125314

[12] Santos, F. \& Martinho, R. Architectural Challenges on the Integration of e-Commerce and ERP Systems: A Case Study. Proceedings of the 23rd International Conference on Enterprise Information Systems (ICEIS 2021), vol. 1, pp. 313-319. 2021. DOI: $10.5220 / 0010494903130319$

[13] Krithika, L., Prabadevi, B., Deepa, N., \& Bhavanasi, S. Integration of E-Commerce System with Various ERP Tools. 2020 International Conference on Emerging Trends in Information Technology and Engineering (icETITE). 2020. DOI:10.1109/icetite47903.2020.43

[14] Goundar, S., Gounder, R., Kumar, A., Chand, L., Singh, R., Whiteside, O., \& Ali, I., Erp implementation challenges and critical success factors. Enterprise Systems and Technological Convergence: Research and Practice, pp. 45. 2021.

[15] Goundar, S., Singh, S., Lata, A., Singh, M., \& Lal, S. Local erp implementation processes and standard methodologies. Enterprise Systems and Technological Convergence: Research and Practice, pp. 63. 2021.

[16] Oh, D.-S., Kim, H.-S., \& Kim, S.-H. A Development of the Customer based On-premise ERP Implementation Process Framework. International Journal of Advanced Smart Convergence, vol. 10(3), pp. 257-278. 2021. DOI:https://doi.org/10.7236/IJASC.2021.10.3.25 $\underline{7}$

[17] Malik, M. O., \& Khan, N. Analysis of ERP implementation to develop a strategy for its success in developing countries. Production Planning \& Control, vol. 32(12), pp. 1020-1035. (2021).

DOI: https://doi.org/10.1080/09537287.2020.1784481

[18] Tarigan, Z. J. H., Suprapto, W., Harjanti, D., Malelak, M. I., \& Basana, S. R. Key user ERP capability maintaining ERP sustainability through effective design of business process and integration data management Key user ERP capability maintaining ERP sustainability through effective design of business process and integration data management (Doctoral dissertation, Petra Christian University). 2021.

[19] Husain, M. B. Challengeing Of Erp Implementation In Malaysia A Case Study. 2021.

[20] Roy, S., \& Sangle, P. S. Exploring Organization Change Management Techniques for Successful ERP Implementation. Journal of Management Research and Analysis, vol. 3(3), pp. 136-144. 2021. DOI: $10.5958 / 2394-2770.2016 .00021 .1$

[21] Amado, A., \& Belfo, F. P., Maintenance and Support Model within the ERP Systems Lifecycle: Action Research in an Implementer Company. Procedia Computer Science, vol. 181, pp. 580-588. $2021 . \quad$ DOI: https://doi.org/10.1016/j.procs.2021.01.205

[22] Thang, V. D., An Hybrid Model For Erp Implementation In SME.2021.

[23] Kakkar, P. Business transformation with cloud ERP. International Journal of Management IT and Engineering, vol. 11(3), pp. 27-31. 2021.

[24] Yoo, B. K., \& Kim, S. H. Analysis of Impact on ERP Customization Module Using CSR Data. Journal of Information Processing Systems, vol. 17(3), pp. 473-488. 2021.

[25] Utomo, S. B., Yuliani, E. W., \& Wulandari, N. Business Process Improvement (BPI) with Enterprise Resource Planning (ERP) Financial \& Control (FICO) and Procurement Modules Using SAP S/4 HANA to Handle Non-Banking Processes in Case Study: PT Bank Mantap. In Journal of Physics: Conference Series (Vol. 1807, No. 1, p. 012004). IOP Publishing. 2021, April.

[26] Dasgupta, H., \& Nayak, A. P. To study the factors affecting the erp implementation project: ERP consultants perspective. European Journal of Molecular \& Clinical Medicine, vol. 7(10), pp. 3895-3907. 2021.

[27] Gavidia, J.V., Junglas, I.A., \& Chou, C.-H. An integrated model of ERP success: the critical role of task-context alignment. Enterprise Information 2021. Dystems. DOI: $10.1080 / 17517575.2021 .1931460$ 
[28] Bender, B., Bertheau, C., \& Gronau, N. Future ERP Systems: A research agenda. In Procs of 23rd International Conference on Enterprise Information Systems. 2021. DOI: 10.5220/0010477307760783

[29] Jesus, C., \& Lima, R., Business processes reconfiguration through the implementation of an enterprise resource planning system. Journal of Applied Engineering Science, pp. 1-10. 2021.

[30] Ploder, C., Dilger, T., \& Bernsteiner, R. Success Factors for the Implementation of a Cloud-based ERP System at Personnel Service Companies. In Software Engineering (Satellite Events). 2021, January.

[31] Skorkovský, J., \& Duranti, C. B. D. Erp System, New Trends, Processes of System Selection, Sales, Implementation And Support. 2014.

[32] Nobari, B. Z., Azar, A., \& Hossein, M. Identifying National Effective Parameters in ERP Implementation Risk Factors in Iran by Multi Grounded Approach. 2018. DOI: 10.22111/JMR.2018.4376

[33] Rizkiana, A. K., Ritchi, H., \& Adrianto, Z. Critical Success Factors Enterprise Resource Planning (ERP) Implementation in Higher Education. Journal of Accounting Auditing and Business, vol. 4(1). 2021. DOI: 10.24198/jaab.v4i1.31551

[34] Domagała, A., Grobler-Dębska, K., Wąs, J., \& Kucharska, E. Post-Implementation ERP Software Development: Upgrade or Reimplementation. Applied Sciences, vol. 11(11), pp. 4937. 2021. DOI: 10.3390/app11114937

[35] Hietala, H., \& Päivärinta, T. Benefits Realisation in Post-Implementation Development of ERP Systems: A Case Study. Procedia Computer Science, vol. 181, pp. 419-426. 2021. DOI: 10.1016/j.procs.2021.01.186

[36] Elhasnaoui, S. Analysis of the Role of IT Governance on ERP Systems Implementation. International Journal of Web-Based Learning and Teaching Technologies (IJWLTT), vol. 16(1), pp. 18-26. 2021. DOI: 10.4018/IJWLTT.2021010103

[37] Chatti, H., \& Zaghdan, M. Identifying the appropriate environment for successful ERP system implementation: A field study in public enterprises. Technology (IJARET), vol. 12(3), pp. 684-697. 2021.
[38] Al Bar, A., Basili, V., Al Jedaibi, W., \& Chaudhry, A. An Analysis of the Contracting Process for an ERP System. Computer Science \& Information Technology (CS\&IT). 2013. DOI: 10.5121/csit.2013.3818

[39] Budiman, K., Putra, A. T., Sugiharti, E., Muslim, M. A., \& Arifudin, R. Implementation of ERP system functionalities for data acquisition based on API at the study program of universities. In Journal of Physics: Conference Series IOP Publishing, vol. 1918, no. 4, pp. 042151. 2021, June.

[40] Huang, Q., Rahim, M., Foster, S., \& Anwar, M. Critical Success Factors Affecting Implementation of Cloud ERP Systems: A Systematic Literature Review with Future Research Possibilities. In Proceedings of the 54th Hawaii International Conference on System Sciences, pp. 4683. 2021, January. DOI: 10.24251/HICSS.2021.569

[41] Nach, H., \& Lejeune, A. Implementing ERP in SMEs: Towards an Ontology Supporting Managerial Decisions. 2008 International MCETECH Conference On E-Technologies. 2008. DOI: 10.1109/mcetech.2008.11

[42] Dasgupta, H., \& Bhadauria, S., Impact of ERP system over different segments of small and medium businesses. European Journal of Molecular \& Clinical Medicine, vol. 7(10), pp. 3808-3818. 2021.

[43] Gërvalla, M., A maturity model for implementation and application of Enterprise Resource Planning systems and ERP utilization to Industry 4.0 (Doctoral dissertation, Budapesti Corvinus $\quad 2021 . \quad$ DOI: 10.14267/phd.2021006

[44] Etehadnezhad, S. Identifying the Aspects and Components Impacting on Enterprise Resources Planning (ERP) Utilization with Human Resources Empowerment Approach in Education. Turkish Journal of Computer and Mathematics Education (TURCOMAT), vol. 12(13), pp. 4948-4959. 2021.

[45] Ylätupa, J., Remote implementation of ERP/MES-system. 2021.

[46] Istanbouli, B. Blueprinting of a Normalized Supply Chain Processes: Results in Implementing Normalized Software Systems. International Journal of Economics and 
Management Engineering, vol. 15(1), pp. 68-72. 2021.

[47] Bhatt, N., Guru, S., Thanki, S., \& Sood, G. Analysing the factors affecting the selection of ERP package: a fuzzy AHP approach. Information Systems and e-Business Management, pp. 1-42. 2021. DOI: 10.1007/s10257-021-00521-8

[48] Nguyen, T., Nguyen, Q., \& Vu, L. The effects of accounting benefit, ERP system quality and management commitment on accountants' satisfaction. Accounting, vol. 7(1), pp. 127-136. 2021. DOI: $10.5267 /$ j.ac.2020.10.005

[49] Sebayang, P., Tarigan, Z. J. H., \& Panjaitan, T. W. S., ERP compatibility on business performance through the inventory system and internal integration. In IOP Conference Series: Materials Science and Engineering, IOP Publishing. vol. 1010, no. 1, pp. 012008. 2021.

[50] Maslii, N. D., Riashchenko, V., Syvolap, L., \& Bezpartochna, O. (2021). Management Approach to Implementation of ERP-System and CBIP for Effective of Enterprise Integration. 2021. DOI: 10.22059/jitm.2021.80739

[51] Wijaya, M. I., \& Utomo, D. Enterprise Resource Planning Modification: A Literature Review. ComTech: Computer, Mathematics and Engineering Applications, vol. 12(1), pp. 33-43. 2021. DOI: $10.21512 /$ comtech.v12i1.6610
[52] Goni, F. A. Review on Enterprise Resource Planning Implementation Roadmap Project Management Perspective.2021.

[53] Utama, M. H., \& Nur'ainy, R. Factors Affecting the Success of Implementation of Enterprise Resource Planning (Case Study: Pt. KimberlyClark). 2021.

[54] Rana, N. S., Shafique, D. M., Ali, A. A., \& Naveed, S. Critical success factors in implementing enterprise resource planning (ERP) system in pakistani organizations. Governance and Management Review, vol. 4(1). 2021.

[55] Chatti, H., Radouche, T., \& Asfoura, E. Framework for the evaluation of the erp implementation success: case study in SMEs. Journal of Management Information and Decision Sciences, vol. 24(4), pp. 1-25. 2021.

[56] Uddin, M. A., Alam, M. S., Mamun, A. A., Khan, T.-U.-Z., \& Akter, A., A Study of the Adoption and Implementation of Enterprise Resource Planning (ERP): Identification of Moderators and Mediator. Journal of Open Innovation: Technology, Market, and Complexity, vol. 6(1), pp. 2. 2019. DOI:10.3390/joitmc6010002 